\title{
Green synthesis of iron oxide nanoparticles using Platanus orientalis leaf extract for antifungal activity
}

https://doi.org/10.1515/gps-2017-0145

Received September 18, 2017; accepted February 2, 2018; previously published online March 24, 2018

Abstract: In this report, aqueous phase green synthesis of iron oxide nanoparticle utilizing Platanus orientalis is elucidated for the first time. The phytoconstituents of the P. orientalis leaf extract serve a dual role as reducing and capping agent during the fabrication of iron oxide nanoparticles. The role of the leaf extract in the synthesis of iron oxide has been briefly demonstrated in this work. The tailored iron oxide particles were characterized using X-ray diffraction, scanning electron microscopy, transmission electron microscopy, energy dispersive X-ray analysis, infrared spectroscopy, ultraviolet-visible spectroscopy, and dynamic light scattering technique. Nonetheless, $\mathrm{X}$-ray diffraction pattern reveals the mixed phase nature of the ensuing iron oxide, i.e. $\alpha-\mathrm{Fe}_{2} \mathrm{O}_{3}$ and $\gamma-\mathrm{Fe}_{2} \mathrm{O}_{3}$. The spherical oxide particles have an average diameter of $38 \mathrm{~nm}$ as determined from transmission electron microscopy. Infrared spectroscopy results confirmed the stabilization of iron oxide nanoparticles by the phytochemicals present in the leaf extract. Iron oxide nanoparticles show significant antifungal activity against Aspergillus niger and Mucor piriformis, employed as model fungi, but found to be more active toward M. piriformis.

Keywords: antifungal activity; green synthesis; iron oxide nanoparticles.

\section{Introduction}

Platanus orientalis ( $P$. orientalis) belonging to the Platanaceae family is known as the tree of Hippocrates in Kashmir, India, and it is locally named as chinar or boonyi

\footnotetext{
*Corresponding author: Henam Sylvia Devi, Special Centre of Nanoscience, PG Department of Physics, National Institute of Technology, Srinagar 190006, India, e-mail: henambi411@gmail.com Muzaffar Ahmad Boda and Mohammad Ashraf Shah: Special Centre of Nanoscience, PG Department of Physics, National Institute of Technology, Srinagar 190006, India

Shazia Parveen and Abdul Hamid Wani: Section of Mycology and Plant Pathology, Department of Botany, University of Kashmir, Srinagar 190006, India
}

כ Open Access. ((c) Br @ 2019 Walter de Gruyter GmbH, Berlin/Boston in India [1]. The $P$. orientalis possesses antihepatotoxic, antioxidant, and cytotoxic activities and elicits antiinflammatory and antinoceptive properties [2]. Tocopherol derivatives, esters of phytol with fatty acids, and several polyphenols are the rich components of this leaf extract $[3,4]$. The use of leaves, flower, stem, root, or whole of plant for synthesis of nanoparticles (NPs) is considered to be a green approach $[5,6]$. The key active component of the leaf extract for synthesis of metal and metal oxide NPs is polyphenols [7]. Plant constituents possessing antioxidant potential such as phenols, flavonoids, tannins, and vitamins have been used for the synthesis of NPs [8]. Green synthesis of metal or metal oxide NPs using plant extracts as biogenic agents has numerous advantages such as cost-effectiveness, atom economy, simplicity, benign, nontoxic, elimination of toxic and dangerous materials, and easy availability [9].

In literature, leaf extract of Aloe vera and Ocimum sanctum were used for preparation of iron oxide NPs as an eco-friendly approach. Gel of $A$. vera leaf potentially acts as a bio-reducing agent for the preparation of metal oxide and metal NPs, semiconductors NPs, etc. [10, 11]. Well-formed iron oxide NPs were successfully synthesized using eucalyptus extract as reducing agent [5]. Besides monometallic oxide NPs, biosynthesis approach can also be adopted for the fabrication of hybrid or composite nanomaterials of iron oxide NPs. The biosynthesis of $\mathrm{Ag} /$ $\mathrm{Fe}_{3} \mathrm{O}_{4}$ nanocomposite has been reported for the first time by Mohaddeseh and coworkers using Euphorbia peplus L. leaf extract as a stabilizing and reducing agent [12]. Additionally, Monireh et al. [8] have reported the green synthesis of $\mathrm{Pd} / \mathrm{RGO} / \mathrm{Fe}_{3} \mathrm{O}_{4}$ nanocomposite using Withania coagulans leaf extract. Sajadi et al. [9] successfully employed the aqueous extract from the seeds of Silybum marianum $\mathrm{L}$. for the preparation of $\mathrm{Cu} / \mathrm{Fe}_{3} \mathrm{O}_{4} \mathrm{NPs}$. Further, Lotus garcinii leaf extract has been also used as effective reducing and capping agent for the biosynthesis of $\mathrm{Ag} /$ reduced graphene oxide $/ \mathrm{Fe}_{3} \mathrm{O}_{4}$ nanocomposite [13].

Iron oxide has been one of the extensively investigated transition metal oxides because of its significant variable oxidation states, crystal structures, low cost, magnetic properties, and environmental friendly nature [14, 15]. Iron oxide NPs were widely used as high-performance anode 
in lithium ion batteries, photoelectrochemical cells, highperformance $\mathrm{CO}$ gas sensor, catalyst for decomposition of phenols and in oxidation of benzyl alcohols with periodic acid, in biomedical field as safe labeling of endothelial progenitor cells, in the field of environmental remediation and food analyzes, immunoassays and magnetic targeted site-specific drug delivery, electromagnetic interference shielding, microwave absorbers, nonlinear optical systems, electrochromic devices, molecular electronics, magnetic recording media, etc. [10, 16-24]. However, few works were reported on the antimicrobial activities of iron oxide NPs $[25,26]$. So the authors have carried out the synthesis of iron oxide NPs using the green approach and examined their antifungal properties on Aspergillus niger and Mucor piriformis, employed as model fungi. As far as our knowledge, iron oxide NPs have been used for the first time to study their effects on the growth of fungi $-A$. niger and $M$. piriformis. The present work has highlighted the easy to scale up method for the fabrication of iron oxide NPs and also contributed to the development of less expensive nanoscale metal oxide particles in the field of antimicrobial activity. Usually, noble metal NPs were extensively designed to study antimicrobial activities. As compared with noble metals, iron oxide materials are easily available and economically beneficial. The tailored nanodimensional iron oxide particles utilizing the leaf extract of $P$. orientalis illustrated their significant antifungal activities.

\section{Materials and methods}

\subsection{Materials}

$\mathrm{Fe}\left(\mathrm{NO}_{3}\right)_{3} \cdot 9 \mathrm{H}_{2} \mathrm{O}(99.8 \%)$ was obtained from Merck Pvt. Ltd., Hyderabad, India. Sabouraud dextrose agar and potato dextrose were purchased from Sigma-Aldrich, New Delhi, India. Hexahit was brought from HPM Chemicals and Fertilizers Ltd. 2nd Industrial Area Behind Haryana Bhawan, Rajasthan, India. All the chemicals were used directly without further purification as it was of analytical grade. Throughout the synthesis processes, double distilled water (DDW) was used. Leaves of $P$. orientalis were collected from the campus of the National Institute of Technology, Srinagar, India. The collected leaves were properly cleaned, dried at room temperature in dark, and further grinded to powder. The fungal organisms $A$, niger and $M$. piriformis used for this test were obtained from the Section of Mycology and Plant Pathology, Department of Botany, University of Kashmir, Srinagar, India.

\subsection{Leaf extract preparation}

In a vial containing $50 \mathrm{ml}$ of DDW, $5 \mathrm{~g}$ of grinded dry leaves were added, and the whole mixture was heated at $70^{\circ} \mathrm{C}$ with constant stirring for $30 \mathrm{~min}$. The obtained leaf extract was subsequently made to cool down to room temperature. This leaf extract was then further filtered using syringe filter of pour size $0.22 \mathrm{~mm}$ in order to remove any impurities present.

\subsection{Synthesis of nanoparticles}

One gram of $\mathrm{Fe}\left(\mathrm{NO}_{3}\right)_{3} \cdot 9 \mathrm{H}_{2} \mathrm{O}$ was added to $10 \mathrm{ml}$ of leaf extract, and it was stirred for $1 \mathrm{~h}$ at $25^{\circ} \mathrm{C}$. The color of the reaction mixture changed from light yellow to dark brown and slowly to red brown, indirectly indicating the formation of iron (III) oxide. To collect the sample, the reaction mixture was centrifuged two to three times at $402.48 \mathrm{~g}$ for $10 \mathrm{~min}$ and washed with alcohol twice. The obtained red-brown color sample of iron oxide was then dried at room temperature.

\subsection{Antifungal activity study}

The antifungal activity of the fabricated NPs was determined by agar well diffusion method. Week-old fungal cultures grown on potato dextrose medium were used to test the antifungal potential of selected NPs. Aliquots of $0.02 \mathrm{ml}$ inocula from each fungal pathogen were inoculated in $20 \mathrm{ml}$ of molten Sabouraud dextrose agar medium in culture tubes. The culture tubes were then homogenized between the hands and poured into $90 \mathrm{~mm}$ Petri plates. The culture plates were then allowed to solidify in laminar airflow chamber, and then wells were made on the agar plate using a $5 \mathrm{~mm}$ standard cork borer. Culture tubes, culture plates and laminar airflow used in this work were brought from Thermo Fischer Scientific, New Delhi, India. Different amounts of NPs $(25,50$, and $75 \mu \mathrm{l}$ of $0.10 \mathrm{mg} / \mathrm{ml} \mathrm{NPs})$ were added to respective wells. Hexahit $0.1 \mathrm{mg} / \mathrm{ml}(20 \mu \mathrm{l} / \mathrm{disc})$ was used as standard (positive control). The effect of fabricated NPs against the fungal pathogens was evaluated and compared with the standard used during the present study. The plates were then sealed and incubated at $25 \pm 2^{\circ} \mathrm{C}$ for 2 days. Finally, the antifungal activity was calculated by measuring the zone of inhibition via standard scale.

\section{Characterizations}

\subsection{Scanning electron microscopy and energy dispersive $\mathrm{X}$-ray analysis}

Scanning electron microscopy (SEM) images were recorded using Hitachi 3600 SEM instrument and energy dispersive X-analysis (EDAX) by using the Thermo Fisher Scientific Ultradry (Madison, WI, USA) instrument of the Central Research Facility of the National Institute of Technology, Srinagar, India.

\subsection{Transmission electron microscopy}

Transmission electron microscopy (TEM) images were recorded using the JEOL 2100F TEM of the Advanced 
Instrumentation Research Facility, Jawaharlal Nehru University.

\subsection{X-ray diffraction}

X-ray diffraction (XRD) of the sample was taken using the D8 Eco Advance Brucker XRD instrument. Dried powder sample of the NPs was used to carry out the diffraction experiment.

\subsection{Fourier transform infrared spectroscopy}

Fourier transform infrared spectroscopy (FT-IR) spectra were obtained by using the SpectrumTwo IR Perkin Elmer instrument. The particles were washed thoroughly, collected, and then dried at room temperature. FT-IR spectra of the particles were recorded by scanning the sample in the range of $400-4500 \mathrm{~cm}^{-1}$.

\subsection{Ultraviolet-visible spectrum}

All ultraviolet-visible (UV-vis) spectra were recorded on the Labtronics LT 2800 V UV-vis spectrophotometer. The absorption spectra of the prepared NPs were recorded by taking the aqueous dispersion of the NPs and scanned in the range of $200-800 \mathrm{~nm}$.

\subsection{Dynamic light scattering}

The sample was prepared by diluting the required amount of sample in DDW and sonicated for $5 \mathrm{~min}$. A minimum of $10 \mathrm{~mm}$ of sample solution was taken and put in a glass or plastic cuvette. This cuvette was placed in the cell holder and scanned in range of $1-100 \mathrm{~nm}$ at room temperature. All the size and $\zeta$ potential measurements in this work have been carried out using the Zeta Sizer Nano ZS90 of Malvern Instruments Ltd. of the National Institute of Technology, Manipur, India.

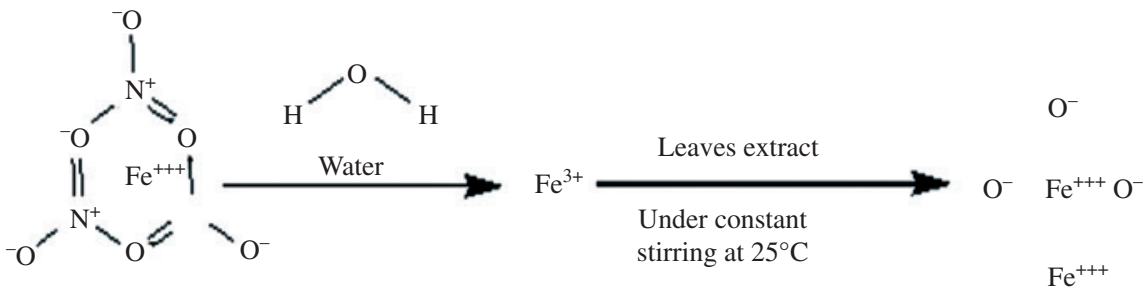

Ferric nitrate

Iron oxide NPs

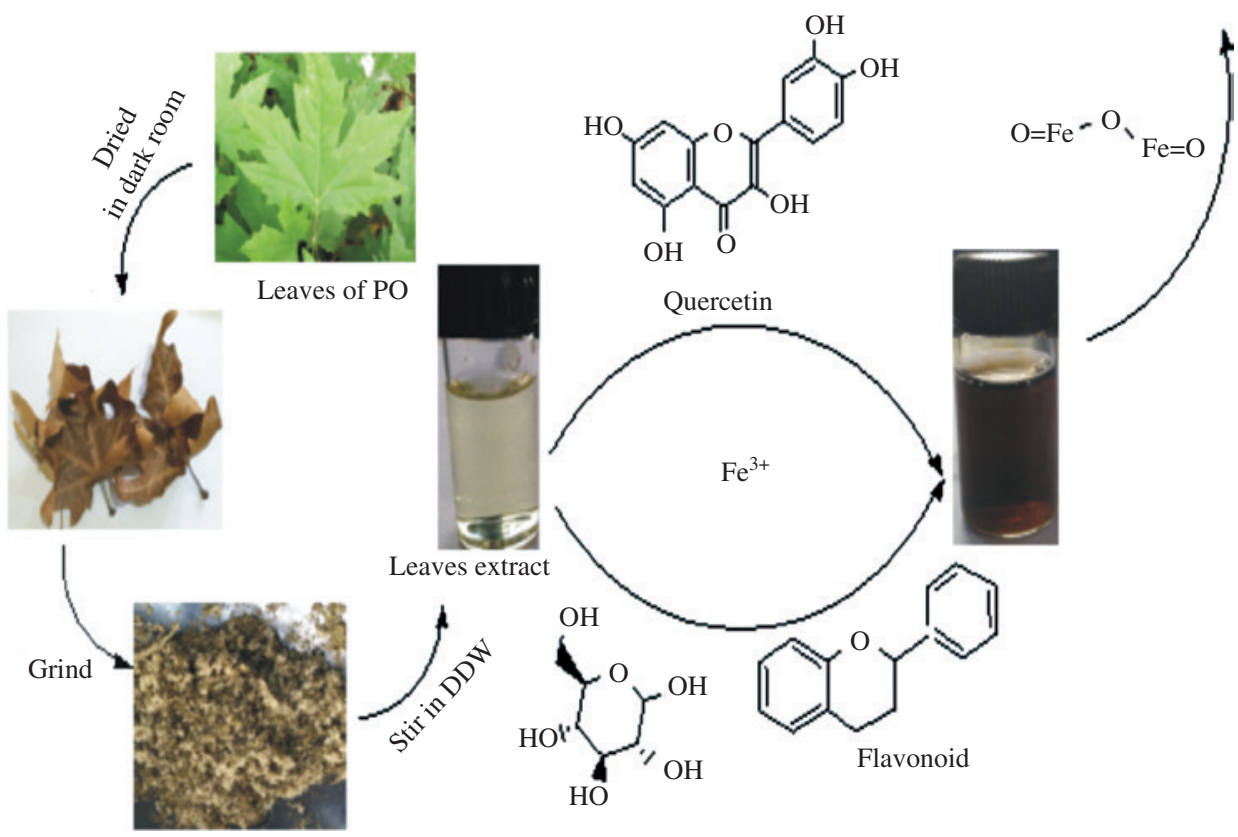

Glucoside

Figure 1: Mechanism involved in the synthesis of iron oxide nanoparticles using the leaf extract of Platanus orientalis. 


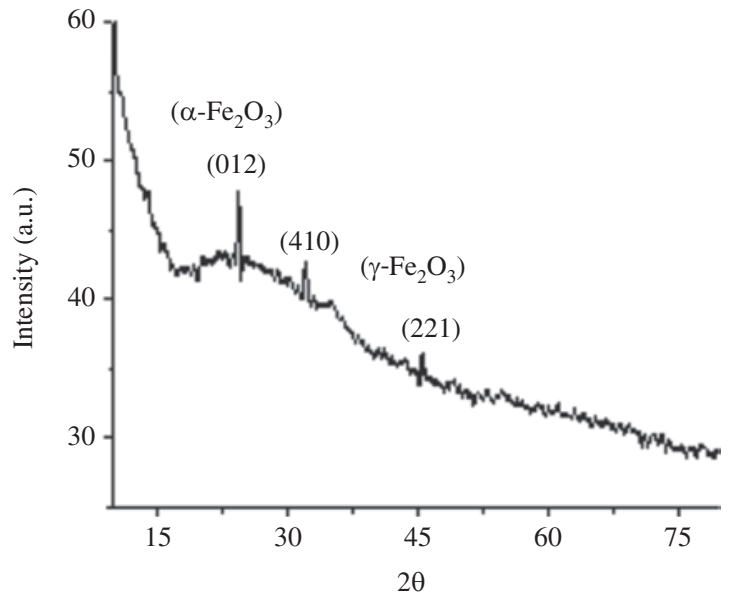

Figure 2: X-ray diffraction pattern of iron oxide nanoparticles.

\section{Results and discussion}

The leaf extract of $P$. orientalis is reported to compose of polyphenols, flavonoids, quercetin, kaempferol, glycosides, and tannins [27]. These phytochemicals are responsible for the formation of NPs [5]. The leaf extract plays a double role in the process of NP synthesis; it reduces the metallic salts to NPs and acts as stabilizing agents hindering the aggregation of the synthesized NPs. The light yellow color of the reaction mixture changes to dark brown on introducing the leaf extract and slowly to red brown, indicating the formation of iron (III) oxide particles. The leaf extract of $P$. orientalis may not be able to reduce $\mathrm{Fe}^{3+}$ to $\mathrm{Fe}^{0}$; instead, the organic components of the leaf extract react with the iron ions to give iron oxide NPs, as the first row transition metals are prone to oxidation [28]. The possible mechanism involved in the synthesis of iron oxide NPs is demonstrated in Figure 1. Confirmation for the formation of iron oxide NPs is given by XRD shown in Figure 2. The XRD results rule out that the iron oxide NPs as obtained is a mixture of $\alpha-\mathrm{Fe}_{2} \mathrm{O}_{3}$ and $\gamma-\mathrm{Fe}_{2} \mathrm{O}_{3}$ revealed by JCPDS-39-1346 [29]. From the XRD data, it can be concluded that particles of iron oxide are crystalline in nature and free from impurities.

The studies on the morphology, surface details, and elemental composition of the fabricated iron oxide NPs

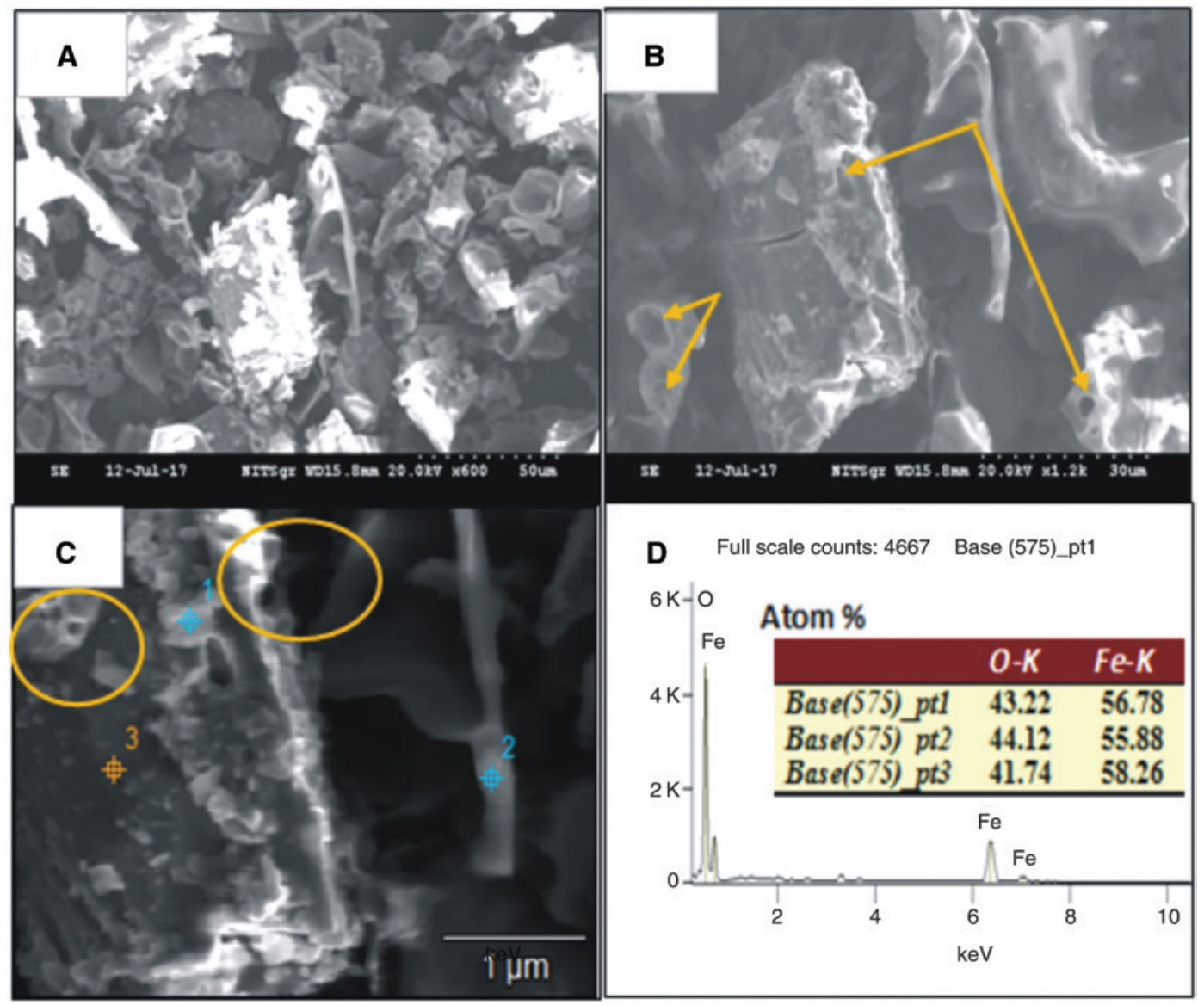

Figure 3: Scanning electron microscopy images of iron oxide nanoparticles $(A-C)$. Energy dispersive X-ray analysis of iron oxide nanoparticles (D). 


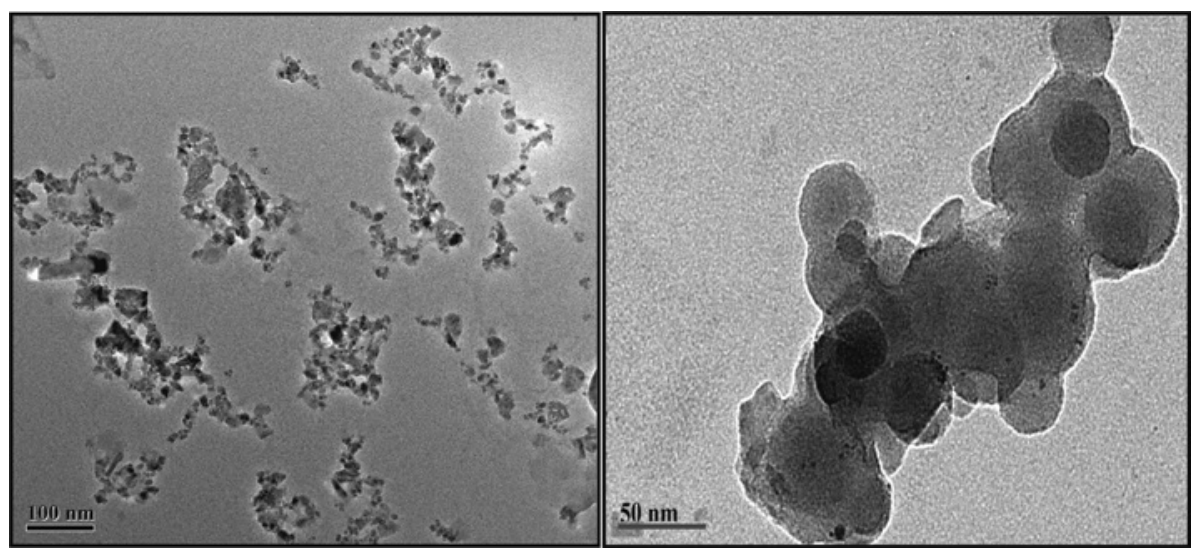

Figure 4: Transmission electron microscopy images of iron oxide nanoparticles.

are made using SEM images and EDAX. SEM images of iron oxide NPs are given in Figure 3A-C. Iron oxide particles have rough surface and are composed of cavitylike structures on the surface as highlighted in Figure 3B and C. EDAX of iron oxide NPs is given in Figure 3D, and it confirms the presence of $\mathrm{Fe}$ and $\mathrm{O}$ in the NPs system. Iron oxide NPs compose of $\mathrm{Fe}$ and $\mathrm{O}$ in weight ratio of 2:3 as given in the inset of Figure 3D. TEM images of iron oxide NPs are highlighted in Figure 4, and from the images, it can be concluded that particles of iron exhibit a spherical shape with an average diameter of $38 \mathrm{~nm}$.

The size of the fabricated iron oxide particles is also determined from dynamic light scattering (DLS) and is delivered in Figure 5. DLS study revealed that particles of iron oxide are in nano range of $78-80 \mathrm{~nm}$ and free from unwanted/dust particles. Some few small size NPs were also observed; however, percentage or intensity of their content was very low. Size determined using DLS is in hydrodynamic size, usually the size determined are large as compared with that from TEM. Furthermore, the optical property of the iron oxide NPs was studied using UV-vis spectroscopy. The spectra of green iron oxide NPs are highlighted in Figure 6. Iron oxide NPs show absorbance at $350 \mathrm{~nm}$, and it is well consistent with literature [11].

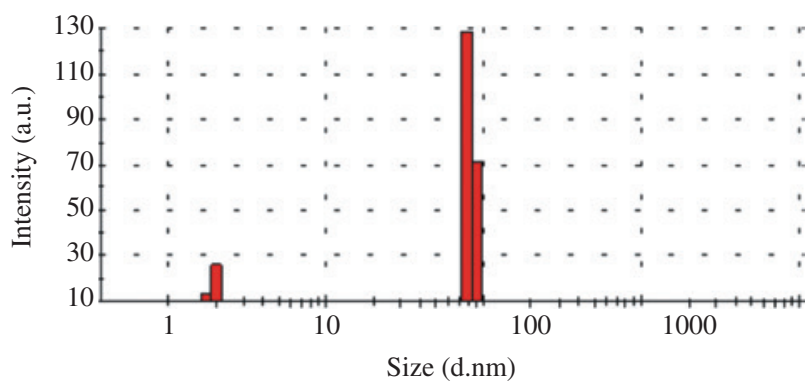

Figure 5: Dynamic light scattering data: plot of intensity vs. size.

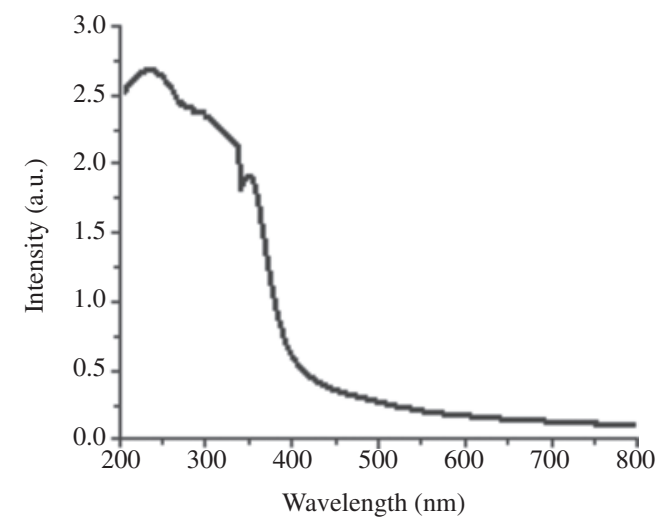

Figure 6: Ultraviolet-visible spectra of iron oxide nanoparticles.

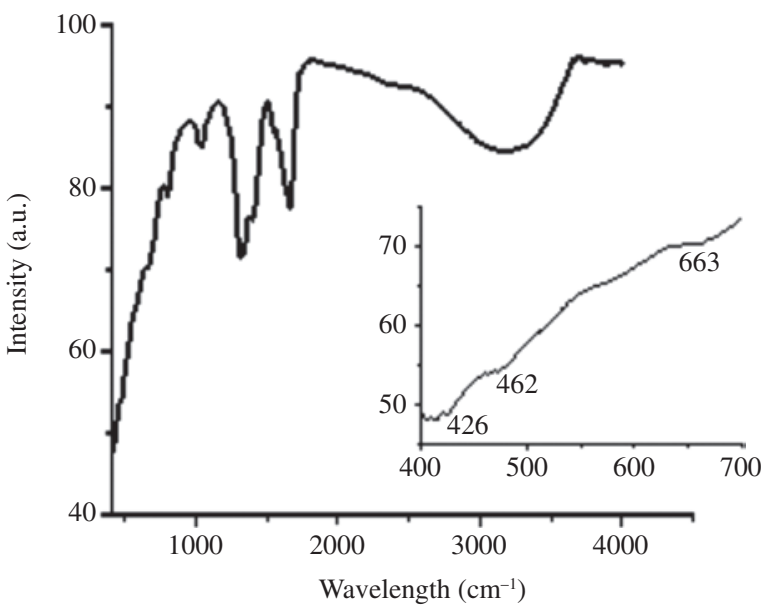

Figure 7: Infrared spectra of iron oxide nanoparticles.

The FT-IR spectra of iron oxide NPs are given in Figure 7. The spectra of iron oxide NPs are composed of stretching mode of aromatic $\mathrm{C}-\mathrm{H}$ at $3196 \mathrm{~cm}^{-1}$, bending vibration of $\mathrm{H}-\mathrm{C}-\mathrm{H}$ at 1315 and $1410 \mathrm{~cm}^{-1}$, C-O and C-C stretching in the range of $1000-1245 \mathrm{~cm}^{-1}$, and out of plane 
Table 1: Antifungal activity of iron nanoparticles.

\begin{tabular}{llrrrr}
\hline Sample no. & Fungus type & & \multicolumn{2}{c}{ Activity against the fungus (mm) } \\
\cline { 3 - 6 } & & Control $(\mathbf{2 0} \boldsymbol{\mu l})$ & $\mathrm{Fe}_{\mathbf{2}} \mathbf{O}_{\mathbf{3}}(\mathbf{2 5} \boldsymbol{\mu l})$ & $\mathrm{Fe}_{\mathbf{2}} \mathbf{O}_{\mathbf{3}}(\mathbf{5 0} \boldsymbol{\mu l})$ & $\mathrm{Fe}_{\mathbf{2}} \mathbf{O}_{\mathbf{3}}(\mathbf{7 5} \boldsymbol{\mu l})$ \\
\hline 1 & Mucor piriformis & 29 & 19 & 23 & 26 \\
2 & Aspergillus niger & 24 & 12 & 14 & 16 \\
\hline
\end{tabular}

Values are represented as mean $\pm 1(\mathrm{SD})$.

bending peak of $\mathrm{C}=\mathrm{C}$ at $795 \mathrm{~cm}^{-1}[30,31]$. Fe-O-Fe stretching vibrations were observed at 663,462 , and $426 \mathrm{~cm}^{-1}$ and are highlighted in the inset of Figure 7 [32]. From this finding, it can be endorsed that iron NPs are formed and are strongly interacted with the components of the leaf extract.

The fungi $A$. niger and $M$. piriformis were used as role model fungi to study the antifungal activities of iron oxide NPs. Few works were reported on the usage of iron oxide NPs as antifungal materials against these two fungi. Spherical iron oxide NPs of 30-40 nm have been used against fungal infection caused by Candida species by Nazanin, and it was reported that the NPs exhibit antifungal potential against the pathogenic Candida spp. [33]. Also, Nehra et al. [34] had successfully demonstrated antifungal activities of chitosan-coated iron oxide NPs against $A$. niger and four other organisms. The mean diameter of inhibition zone of the fabricated chitosan-coated NPs was in the range of $14.5-18.5 \mathrm{~mm}$,
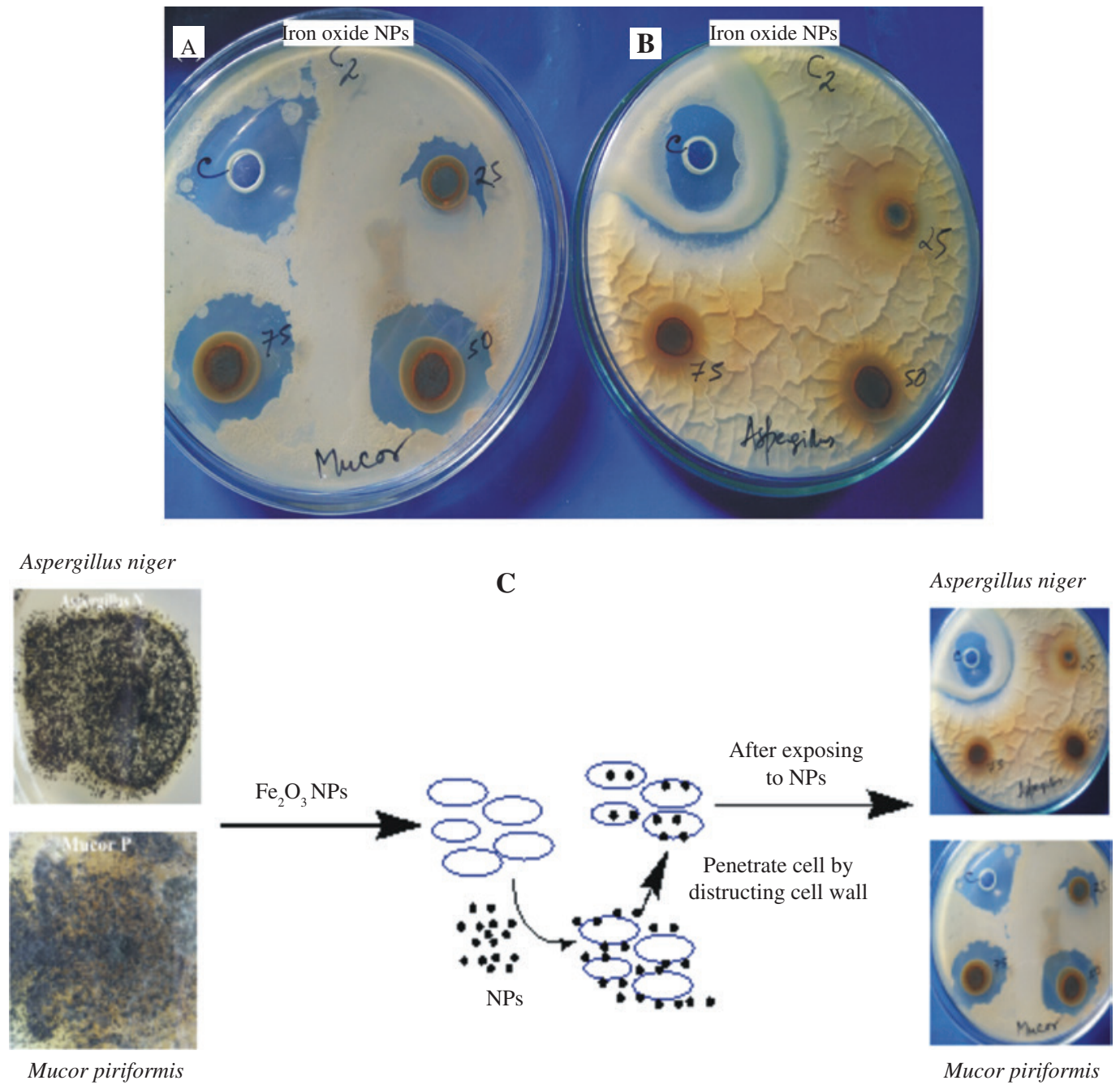

Figure 8: Antifungal activity of iron oxide nanoparticles against (A) Mucor piriformis, (B) Aspergillus niger, and (C) diagrammatic presentation of the antifungal activity. 
which is almost comparable with our findings. Activities of iron oxide NPs are summarized in Table 1 and presented in Figure 8. NPs have large surface-to-volume ratio, so it can strongly adhere to the cell surface of fungus. Also, due to its small size, it can directly penetrate into the cell and damage the cell wall. Inactivation of fungus by iron oxide NPs involves the direct interaction between NPs and cell surfaces, which affects the permeability of membranes where NPs enter and induce oxidative stress in fungus cells, subsequently resulting in the inhibition of cell growth and eventually cell death [35]. Possibilities of membrane damage caused by direct or electrostatic interaction between iron oxide NPs and cell surfaces, cellular internalization of NPs, and the production of active oxygen species such as $\mathrm{H}_{2} \mathrm{O}_{2}$ in cells due to metal oxides have been reported in the literature [36]. Moreover, iron oxide NPs synthesized using $P$. orientalis show significant antifungal activities against $M$. piriformis as compared with $A$. niger as displayed in Figure 8A. The authors strongly believe that iron oxide NPs may have robustly interacted with the cell surface of $M$. piriformis that resulted in greater impact on $M$. piriformis. The activity of iron NPs against fungus is diagrammatically demonstrated in Figure 8C.

\section{Conclusion}

The use of $P$. orientalis leaf extract is a felicitous method for the synthesis of iron oxide NPs. The method adopted is highly benign, cost-effective, and sustainable. The iron oxide NPs fabricated using this route are stable, crystalline, free from impurities, and possess efficient antimicrobial activity. The tailored iron oxide NPs show compelling effect on the growth of the fungi $M$. piriformis and A. niger. The antifungal activity of iron oxide NPs against M. piriformis is 1.6-fold greater than that of A. niger, and it is attributed to the greater surface interaction of the iron NPs to M. piriformis. The application of iron oxide NPs in the field of antimicrobial activity is still in its infancy. We can draw the inference that nanoscale iron oxide particles of uniform size can be used as future antidote of fungi and hope that this work gives the readers some inspiration to explore novel routes for the synthesis of iron oxide nanomaterials of various morphology for future antimicrobial application in nanomedicine.

Acknowledgments: The authors are very thankful to DST for funding the project. The authors are grateful to Dr. Thiyam David and Dr. Henam Premananda Singh,
Department of Chemistry National Institute of Technology, Manipur, India, for providing technical support. We are very thankful to Dr. M. Ikram, Head of the Physics Department, National Institute of Technology, Srinagar, India, for allowing us to record the UV-vis spectra.

\section{References}

[1] Hajhashemi V, Ghannadi A, Mousavi S. Res. Pharm. Sci. 2011, 6, 123-128.

[2] Thai QD, Tchoumtchoua J, Makropoulou M, Boulaka A, Meligova AK, Mitsiou DJ, Mitakou S, Michel S, Halabalaki M, Alexis MN, Skaltsounis LA. Phytochemistry 2016, 130, 170-181.

[3] Abdullaev UA, Rashkes YV, Khidyrova NK, Rashkes AM. Chem. Nat. Cmpd. 1994, 30, 332-338.

[4] El-Alfy TS, El-Gohary HMA, Sokkar NM, Sleem AA, Al-Mahdy DA. Nat. Prod. Commun. 2008, 3, 199-203.

[5] Maria MC, Marta LG, Jose LB, Roberto H, Manuel ESDV. Chem. Eng. J. 2016, 301, 83-91.

[6] Devatha CP, Arun KT, Shweta YK. J. Cleaner Prod. 2016, 139, 1425-1435.

[7] Oxana VK, Dias HVD, Boris IK, Betsabee OP, Victor MJP. Trends Biotechnol. 2013, 31, 240-248.

[8] Monireh A, Mahmoud N, Mohammad S. J. Colloid Interface Sci. 2016, 465, 249-258.

[9] Sajadi SM, Nasrollahzadeh M, Maham M. J. Colloid Interface Sci. 2016, 469, 93-98.

[10] Debarati M, Sourja G, Swachchha M, Annapurna K. J. Environ. Chem. Eng. 2016, 4, 639-650.

[11] Balamurughan MG, Mohanraj S, Kodhaiyolii S, Pugalenthi V. J. Chem. Pharm. Sci. 2014, 4, 201-204.

[12] Mohaddeseh S, Mahmoud N, Sajadi SM. J. Colloid Interface Sci. 2017, 497, 1-13.

[13] Mehdi M, Mahmoud N, Sajadi SM, Mehdi N. J. Colloid Interface Sci. 2017, 497, 33-42.

[14] Cai J, Chen S, Ji M, Hu J, Ma Y, Qi L. CrystEngComm 2014, 16, 1553-1559.

[15] Nguyen DC, Dinh QK, Tran TH, Duong TQ, Pham HV, Tran DL, Nguyen DH, Nguyen, VH. Mater. Res. Bull. 2015, 68, 302-307.

[16] Moushumi H, Indranirekha S, Jadumoni D, Chandan T, Manash RD. Letters 2016, 164, 480-483.

[17] Wu C, Zhuang Q, Tian L, Cui Y, Zhang X. Mater. Lett. 2013, 107, 27-30.

[18] Chao G, Fang Z, Qianqian L, Tingting L, Nana P, Zhengang L. Appl. Catal., B 2017, 204, 566-576.

[19] Bappi P, Bishal B, Debraj DP, Siddhartha SD. Catal. Commun. 2015, 69, 48-54.

[20] Elisa C, Veronica B, Anna M, Joan M, Anna R, Anna R. Acta Biomater. 2014, 10, 3775-3785.

[21] Al-Saad KA, Amr AA, Hadi DT, Arar RS, AL-Sulaiti MM, Abdulmalik TA, Alsahamary NM, Kwak JC. Arab J. Nucl. Sci. Appl. 2012, 45, 335-346.

[22] Kakarla RR, Wonjung P, Byung CS, Jaegeun N, Youngil L. J. Colloid Interface Sci. 2009, 335, 34-39.

[23] Kakarla RR, Kwang PL, Anantha IG. J. Appl. Polym. Sci. 2007, 106, 1181-1191.

[24] Kakarla RR, Kwang PL, Ju YK, Youngil L. J. Nanosci. Nanotechnol. 2008, 8, 5632-5639. 
[25] Trang VT, Tam LT, Nguyen VQ, Tran QH, Nguyen TT, Doan QT, Nguyen DC, Pham AT, Hoang VT, Anh-Tuan L, Phan VN. J. Electron. Mater. 2017, 46, 3381-3389.

[26] Robert P, Jiri T, Martina K, Ales P, Libor K, Jan F, Milan K, Katerina T, Radek Z. Biomaterials 2011, 32, 4704-4713.

[27] Syed I, Gulzar AB, Mudasar A, Hilal AG, Bashir AG, Azra NK, Seema A, Mudasir AT. Pharmacologia 2016, 7, 217-222.

[28] Raja D, Pradip P, Rahul B, Pankaj P. Nanoscale 2012, 4, 591-599.

[29] Hongtao C, Yan L, Wanzhong R. Adv. Powder Technol. 2013, 24, 93-97.

[30] Donald LP, Gary ML, George SK, James AV. Introduction to Spectroscopy, 5th ed., Cengage Learning: Boston, MA, 2014.
[31] Kim IH, Park EJ, Park CH, Han SH, Seo HO, Kim YD. Catalysis Today 2017, 295, 54-64.

[32] Rahman MM. In Nanotechnology and Nanomaterials, Rahman MM, Khan SB, Jamal A, Faisal M, Aisiri AM, Eds., InTech: London, 2011.

[33] Nazanin SS, Samira S, Ali RI. IET Nanobiotechnology 2017, 11, 883-888.

[34] Nehra P, Chauhan RP, Garg N, Verma K. Br. J. Biomed. Sci. 2018, 75, 13-18.

[35] Yanping X, Yiping H, Peter LI, Tony J, Xianming S. Appl. Environ. Microbiol. 2011, 77, 2325-2331.

[36] Liu Y, He L, Mustapha A, Li H, Hu ZQ, Lin M. J. Appl. Microbiol. 2009, 107, 1193-1201. 